\title{
ERYTHROPOIETIN HAS AN ADDITIVE CYTOPROTECTIVE AND BENEFICIAL EFFECT TO SILDENAFIL IN A MODEL OF DIASTOLIC HEART FAILURE IN RATS
}

\author{
BY \\ Essam F. Alalkamy ${ }^{1}$, Hesham A Awad ${ }^{1}$, Soheir A Abdel Wahed ${ }^{1}$, Mira F Yousuf ${ }^{2}$, \\ Inas A Harb ${ }^{1}$ \\ FROM \\ ${ }^{1}$ Medical Pharmacology Dpt., Faculty of Medicine, Cairo University, Egypt; ${ }^{2}$ \\ Histology Dpt., Faculty of Medicine, Cairo University, Egypt
}

\begin{abstract}
$\underline{\text { Abstract }}$
Development of new forms of interventions for diastolic heart failure (HFpEF) remains a challenging task. The aim: Assessing the effect of combining erythropoietin and sildenafil on the left ventricle "LV" functions and morphometry in N $\mathrm{N}^{\mathrm{G}}$-nitro-Larginine methyl ester (L-NAME)-induced HFpEF model in rats. Method: Forty-eight female albino rats were randomly assigned to one of six treatment groups: "C" (Control), "L" (L-NAME-treated), "L+M" (L-NAME+milrinone-treated), "L+S" (LNAME+sildenafil-treated), "L+E" (L-NAME+erythropoietin-treated), and " $\mathbf{L}+\mathbf{S}+\mathbf{E}$ " (L-NAME+sildenafil+erythropoietin-treated). Assessment was done by morphometric examination, LV ejection fraction (LVEF) and fraction of shortening (LVFS)], ECG changes, and mean time to peak tension (TPT) and to complete relaxation (TCR) of isometric contraction of LV muscle strip stimulated by single (TPT-S \& TCR-S) and by repeated pulses (TPT-R \& TCR-R), respectively. $\underline{\text { Results: }}$ L-NAME resulted in cardiac dysfunction with significant reduction in the mean "LVEF" and "LVFS", and prolonged both the mean "TPT-R" and "TCR-R". Milrinone and sildenafil treatment significantly corrected these parameters. In addition, erythropoietin significantly ameliorated "LVEF" and "LVFS" and shortened "TPT-S". Similarly, "sildenafil+erythropoietin" treatment significantly corrected the measured parameters; however, they were insignificantly different from that of sildenafil only treatment. Morphometrically, sildenafil treatment resulted in significant but partial improvement in L-NAME-induced myocardial injury. Meanwhile, erythropoietin treatment showed more improvement. Moreover, combination treatment showed the best histologic picture in all of the treated groups. Conclusion: Sildenafil was able to improve cardiac functions mainly by accelerating diastolic relaxation. Addition of erythropoietin to sildenafil improved its cytoprotective effect.
\end{abstract}

Key words: Diastolic heart failure, sildenafil, erythropoietin, echocardiography, left ventricle, electrical stimulation, cardiac morphometry.

\section{$\underline{\text { Rationale \& Background: }}$}

The profile of heart failure (HF) in the community has changed in recent decades with a relative increase in frequency of diastolic HF with preserved ejection fraction $(\mathrm{HF} p \mathrm{EF})$ (Vasan et al. 2018). In addition, despite the advances in the management of the systolic type, no treatment has yet been shown, satisfactorily, to reduce morbidity or mortality in patients with HFpEF (Fukuta et al. 2016). 
Several recent findings indicate that a defective NO signaling is involved in left ventricular (LV) diastolic abnormalities and remodeling (Guazzi et al. 2011). A new hypothesis for HFpEF development proposes that certain comorbid conditions as obesity can induce a systemic proinflammatory state with coronary microvascular endothelial inflammation. This reduces nitric oxide bioavailability, cyclic guanosine monophosphate content and protein kinase G (PKG) activity in adjacent cardiomyocytes. Reduced PKG activity decreases phosphorylation of myocyte titin protein and results in increased hypertrophy and resting tension. Finally, stiffness and fibrosis contribute to diastolic HF development (Paulus and Tschöpe, 2013). In addition, upregulation of PDE5 is reported in many chronic cardiovascular diseases including congestive HF (Pokreisz et al. 2009). Such up-regulation is thought to contribute to vascular and cardiac pathophysiology and to drug tolerance (Kass et al. 2007). On the other hand, myocardial relaxation (lusitropy) is accelerated by adrenergic stimulation. Positive lusitropy is generally attributed to the increased $\mathrm{Ca}^{2+}$ uptake rate by the sarcoplasmic reticulum (SR) (Fukuda et al. 2008).

Previous experimental studies of PDE5 inhibitors as sildenafil in failing murine and human hearts showed significant beneficial effects on dilation, hypertrophy, remodeling, and dysfunction associated with increased protein kinase $G$ activity, shortening, and relaxation of sarcomere and enhancement of transients and decay of $\mathrm{Ca}^{2+}$ in the isolated myocytes (Nagayama et al. 2009; Guazzi et al. 2011 and Gong et al. 2013). However, the role of PDE5 and the mechanisms by which PDE5 is upregulated in the pathophysiological process of HF are not fully clarified.

Erythropoietin (EPO) which is traditionally used for increasing survival and promoting proliferation of erythroid progenitor cells, has been recently suggested as a potential therapy for HFpEF. EPO has been shown to render organ protection in various experimental models of acute ischemia and improves cardiac function in experimental models of chronic myocardial dysfunction and improved microvascularisation of the myocardium through Akt-endothelial nitric oxide synthase (eNOS) activation (Urao et al. 2006; Hefer et al. 2012 and Westenbrink et al, 2007).

These findings suggest that, patients with DHF can gain benefit from using PDE5 inhibitors by increasing phosphorylation of titin protein and decreasing stiffness of cardiac muscle due to improved availability of cGMP. In addition, EPO can activate eNOS and improves microvascularisation and cardiac function.

The present study was designed to explore the possible therapeutic benefit of adding erythropoietin to the PDE5 inhibitor (sildenafil) on cardiac dysfunction and morphometry in a model of HFpEF in female albino rats induced by L-NAME in comparison with milrinone as a standard reference drug.

\section{Materials and Methods}

\section{A. Animals:}

Forty-eight female albino rats weighting 350-400g were purchased from the experimental animal house of Faculty of Medicine, Cairo University. They were handled according to the guidelines of local ethics committee which comply with the international laws for use and care of laboratory animals. Rats were put in metal cages maintained at temperature $25 \pm 2{ }^{\circ} \mathrm{C}, 12: 12 \mathrm{~h}$ light-dark cycle and $50 \pm 5 \%$ relative humidity and were allowed a week for acclimatization before starting the study. All 
animals had free access to water and normal rat chow. Females were chosen for the model of HF depending on previous work of Curl et al., (2008), who reported significantly weaker contractile force in female than male papillary muscles in response to altered extracellular $\mathrm{Ca}^{2+}$.

B. Experimental Design:

Rats were randomly assigned to one of six experimental groups (8 rats each): "C": Control untreated, "L" (HFpEF model): L-NAME-treated, "L+M": LNAME+Milrinone-treated, "L+S": $\quad$ L-NAME+Sildenafil-treated, "L+E": $\quad$ LNAME+Erythropoietin-treated, and "L+S+E": L- NAME+Sildenafil+Erythropoietintreated groups.

All treatments started on day zero, dissolved in drinking water and were given by oral gavage technique except erythropoietin according to the following regimen: LNAME (Santa Cruz Biotechnology, USA: dose: 100mg/kg/day $/ 8$ weeks) (FerreiraMelo et al. 2011); milrinone (powder, Sigma-Aldrich, USA: $0.5 \mathrm{mg} / \mathrm{kg} / \mathrm{day} / 21$ days) (Jain et al. 1991); sildenafil (EREC, 100mg scored tablets; Adwia Pharmaceuticals Co. Egypt: $100 \mathrm{mg} / \mathrm{kg} /$ day/8 weeks) (Takimoto et al. 2005); erythropoietin (darbepoetinalfa) (Aranesp, $40 \mu \mathrm{g} / \mathrm{ml}$ vial, Amgen Inc., USA: $0.4 \mu \mathrm{g} / \mathrm{kg}$ was injected intraperitoneally once every three weeks for 3 doses) (Westenbrink et al. 2007).

A) In-vivo studies

1) Echocardiographic Measurement of LVEF (left ventricular ejection fraction) and LVFS (left ventricular fraction of shortening):

Rats were anesthetized with a single intraperitoneal (ip) injection of ketamine $(75 \mathrm{mg} / \mathrm{kg})$ and midazolam $(7.5 \mathrm{mg} / \mathrm{kg})$. Animals were examined in supine position by transthoracic echocardiography accomplished by using MyLab 30 Gold vet Esaote Italy Phased array probe 8 - 4 MHz. High frame rate was achieved by software modification for use in rodents, and the focus area was $10-25 \mathrm{~mm}$ from the transducer with images, each composed of five to nine consecutive heart cycles (Guazzi et al. 2011).

\section{2) ECG recording for measuring QT interval}

Rats, anesthetized by $1 \mathrm{~g} / \mathrm{kg}$ intraperitoneal urethane (Tanida et al. 2005). Animals were put on heater table to assist animal warming, positioning and fixation during the ECG monitoring. Recording ECG was done by inserting the leads of ECG unit of the PowerLab (PowerLab Data Acquisition 4/30 with Labchart Pro "ML866/P", ADinstruments, Australia) into both upper and one lower limbs of rats (Abbott et al. 2004).

B) In Vitro studies:

3) Isometric contractility recording of isolated left ventricle strip to single electrical stimulation to demonstrate cardiac muscle contractility and measuring time to peak pressure and time to complete relaxation (Satoh et al. 2001 and Afzal et al. 2011)

4) Cumulative response recording (time to peak pressure and time to relaxation) after repeated impulses of electrical stimulation.

After ECG recordings, the anesthetized rats were sacrificed by excising the heart and the papillary muscle was dissected and kept in Krebs' buffer (Satoh et al. 2001). Then muscle was clamped at one end by a clip positioned over platinum electrodes embedded in the electrode body (Cardiac muscle stimulating electrode, Radonti Model 
160156). This electrode was designed for punctate stimulation of cardiac muscles and connected to an electrical stimulator unit (FE155, Power Lab Stimulator HC, ADinstruments, Australia) through MLAC36 Stimulator HC Lead. The other tendinous end of the muscle was secured to an isometric force transducer (MLT0201/RAD, Panlab, Spain) for detecting the changes in isometric tension. The transducer was connected to PowerLab Data Acquisition (PowerLab 4/30 with Labchart Pro "ML866/P", ADinstruments, Australia) through an amplifier (Bridge Amp ML221, ADinstruments, Australia). The muscle preparation was then mounted in Radnoti Tissue and Organ Bath (Model 1583 Series, volume $10 \mathrm{ml}$, Radnoti Glass Technology Inc., Monrovia, California USA) containing the solution maintained at $30^{\circ} \mathrm{C}$ and continuously bubbled with carbogen for about one hour to gradually lengthen and attain maximal developed tension. Stimulation was done at a voltage $10 \%$ above threshold on two steps:

- First step (single stimulation $1 \mathrm{hz}$, pulse duration $0.1 \mathrm{~ms}$, amplitude $20 \mathrm{~mA}$ ).

- Second step (high frequency 5 consequent pulses stimulation (simulating cumulative dose response curve of ventricular muscle) at $5 \mathrm{hz}$, pulse duration $0.1 \mathrm{~ms}$, amplitude $20 \mathrm{~mA}$ ).

Time to peak tension (time from the onset of twitch to peak tension) and time to complete relaxation (time from peak tension to complete relaxation) in response to single pulse stimulation (TPT-S \& TCR-S) and to repeated cumulative high frequency pulse stimulation (TPT-R \& TCR-R) respectively, were measured and recorded by an electronic timer unit of the PowerLab after the end of the experiment.

C) Microscopic morphometric examination of $\mathbf{L V}$ for assessment of myocardial hypertrophy and injury (Rocha et al. 2000)

The histopathological sections of LV were stained with hematoxylin and eosin. Sections were photographed using an Olympus DP27 digital camera attached to CellSens software computer system. Morphometric study was done using Leica Qwin 500 software system attached to Olympus BX40 microscope and Panasonic digital camera. Measurements done included cardiac myocyte diameters, nuclei diameters and ratio between nuclear and myocyte diameters (of the same fibers). Measurement of fiber diameter was done on areas of fibers away from branching and anastomoses sites. Measurements were taken 25 times from every sample in non-overlapping serial fields with exclusion of necrotic fibers (Maeda et al. 1995).

\section{Statistical analysis:}

All values are presented as means \pm SD. Mean data from each study group were compared by one-way analysis of variance (One-way ANOVA), All data were submitted to a computerized statistical treatment using Statistical Package for Social Sciences (SPSS) (for windows, Student version 10, USA) and the Microsoft computer program. $\mathrm{P}$ values less than 0.05 were considered to be statistically significant.

\section{Results}

1- Echocardiographic Examination of Left Ventricle to measure LVEF and LVFS: $\mathrm{N}^{\mathrm{G}}$-nitro-L-arginine methyl ester (L-NAME) treatment resulted in significant reduction in the mean LVEF and LVFS compared to that recorded in the control group "C" rats. Meanwhile, treatment with milrinone, sildenafil, erythropoietin or combination of sildenafil plus erythropoietin in groups; " $\mathrm{L}+\mathrm{M}$ ", " $\mathrm{L}+\mathrm{S}$ ", " $\mathrm{L}+\mathrm{E}$ " and " $\mathrm{L}+\mathrm{S}+\mathrm{E}$ " significantly increased the mean LVEF and LVFS compared to that recorded in group 
"L". However, the addition of erythropoietin to sildenafil had no significant corresponding further increase in these two parameters (Table 1).

\section{2- ECG (QT interval)}

The mean QT interval showed significant prolongation in group " $L$ ", compared to that recorded in normal group "C" while only milrinone and sildenafil treatments significantly shortened this prolongation. On the other hand, erythropoietin given alone resulted in insignificant tendency for shortening of the QT interval. Moreover, addition of erythropoietin to sildenafil resulted in no more significant shortening than that produced by sildenafil only (Table 1, Figure 1).

Table (1) shows the mean percent $( \pm \mathrm{SD})$ of left ventricular ejection fraction (LVEF) \& left ventricular fraction of shortening (LVFS) and the mean QT interval of different rat groups.

\begin{tabular}{|l|l|l|l|}
\hline Group & $\begin{array}{l}\text { The mean } \\
\text { LVEF }\end{array}$ & The mean LVFS & $\begin{array}{l}\text { The mean QT } \\
\text { interval }\end{array}$ \\
\hline Group "C" & $77 \% \pm 0.03$ & $41 \% \pm 0.03$ & $42 \mathrm{~ms} \pm 0.008$ \\
\hline Group "L" & $52 \% \pm 0.1^{\mathrm{a}}$ & $25 \% \pm 0.06^{\mathrm{a}}$ & $69 \mathrm{~ms} \pm 0.005^{\mathrm{a}}$ \\
\hline Group "L+M" & $74 \% \pm 0.07^{\mathrm{b}}$ & $39 \% \pm 0.06^{\mathrm{b}}$ & $49 \mathrm{~ms} \pm 0.003^{\mathrm{b}}$ \\
\hline Group "L+S" & $78 \% \pm 0.08^{\mathrm{b}}$ & $42 \% \pm 0.07^{\mathrm{b}}$ & $53 \mathrm{~ms} \pm 0.006^{\mathrm{a}+\mathrm{b}}$ \\
\hline Group “L+E" & $71 \% \pm 0.18^{\mathrm{b}}$ & $40 \% \pm 0.15^{\mathrm{b}}$ & $64 \mathrm{~ms} \pm 0.004^{\mathrm{a}+\mathrm{b}}$ \\
\hline $\begin{array}{l}\text { Group } \\
\text { "L+S+E" }\end{array}$ & $73 \% \pm 0.09^{\mathrm{b}}$ & $38 \% \pm 0.06^{\mathrm{b}}$ & $55 \mathrm{~ms} \pm 0.003^{\mathrm{a}, \mathrm{b}}$ \\
\hline
\end{tabular}

Values are represented as Mean \pm Standard deviation (SD)

Group "C" = Control untreated/normal, Group "L" = L-NAME-treated, Group "L+M" $=$ L-NAME+milrinone-treated, Group "L+S" = L-NAME+sildenafil-treated, Group $" \mathrm{~L}+\mathrm{E} "=\mathrm{L}-\mathrm{NAME}+$ erythropoietin-treated, and Group "L+S+E" = LNAME+sildenafil+erythropoietin-treated.

a Significant difference compared to group C: control C (normal group). ( $p$ value $\leq$ $0.05)$

${ }^{b}$ Significant difference compared to group L: (L-NAME treated group). ( $p$ value $\leq$ $0.05)$

${ }^{\mathbf{c}}$ Significant difference compared to group L+S: (L-NAME+Sildenafil treated group). $(p$ value $\leq 0.05)$ 


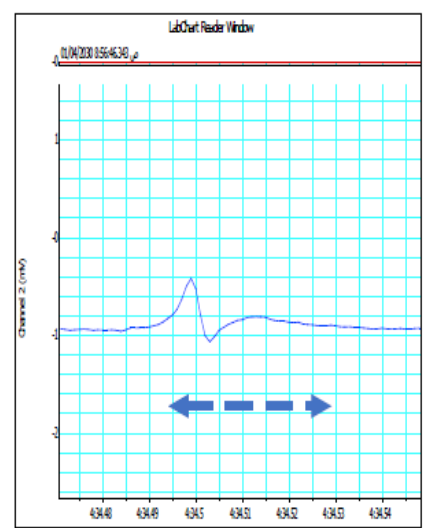

Group "C"

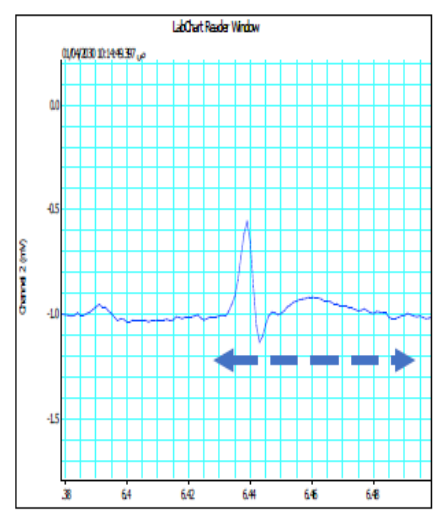

Group " $\mathrm{L}+\mathrm{S}$ "

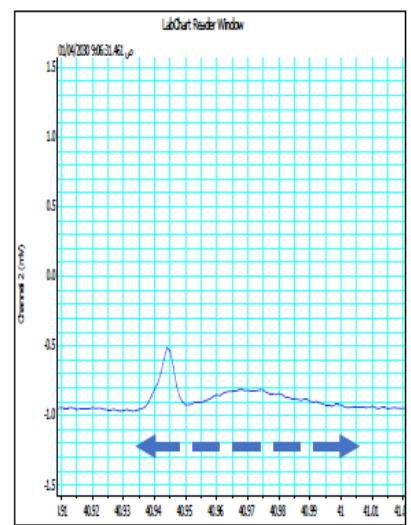

Group "L"

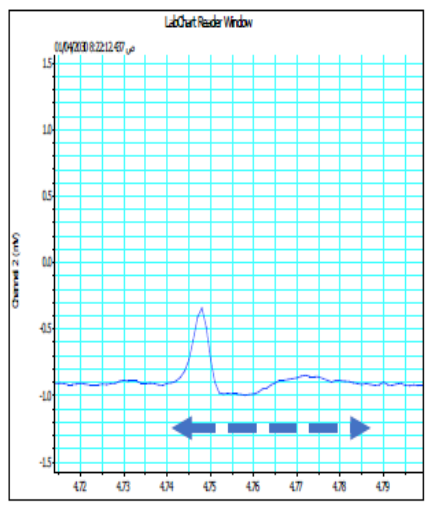

Group "L+E"

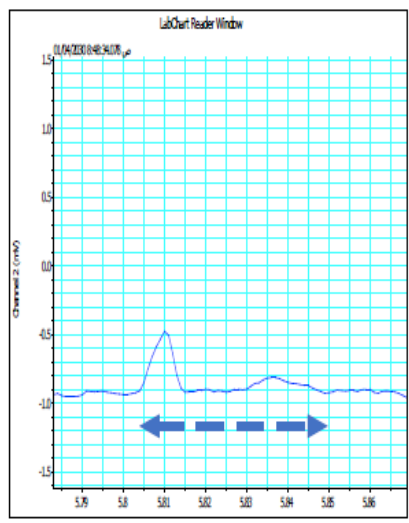

Group "L+M"

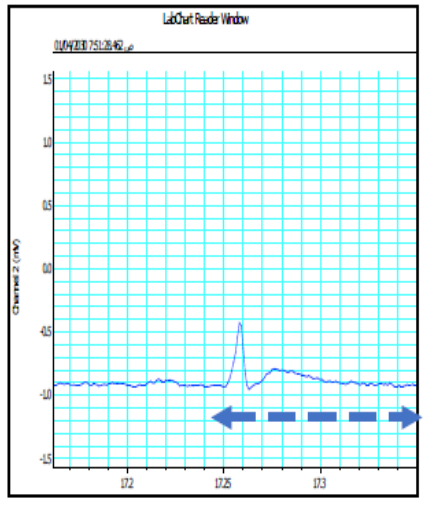

Group " $\mathrm{L}+\mathrm{S}+\mathrm{E}$ "

Figure (1): Average view of the mean QT interval of the ECG of the different rat groups. Group C (control untreated): normal QT interval. Group "L" (L-NAME-treated group): prolonged QT interval compared to normal group. Group "L+M" (LNAME+milrinone-treated): shortening of QT interval compared with group "L". Group "L+S" (L-NAME+sildenafil-treated): shortening of QT interval compared with group "L". Group "L+E" (L-NAME+erythropoietin-treated): shortening of QT interval compared with group "L". Group "L+M+S" (L-NAME+erythropoietin+sildenafiltreated): shortening of QT interval compared with " $\mathrm{L}$ "

\section{3) Isometric Contractility:}

\section{a- Response to single pulse stimulation}

L-NAME treatment insignificantly changed the mean "TPT-S" and "TCR-S" in response to single pulse stimulation. Meanwhile, both milrinone and sildenafil treatments significantly accelerated relaxation i.e. decreased the mean (TCR-S) compared to that recorded in both group "C" and "L". In addition, the mean "TPT-S" was significantly decreased by milrinone compared to that recorded in both groups " $\mathrm{C}$ " and "L". However, it was significantly decreased by sildenafil treatment compared to that recorded only in group "L" but not to that recorded in group "C". On the other hand, erythropoietin significantly shortened the mean "TPT-S" i.e. accelerated contraction, but insignificantly shortened the mean "TCR-S" compared to that recorded in group "L". Moreover, addition of erythropoietin to sildenafil significantly shortened both the mean "TPT-S" and "TCR-S" compared to group "L". However, these shortenings were insignificantly different from sildenafil only treatment (Table 2, Figure 2). 
b- Cumulative response of Repeated Stimulation with High Frequency Pulse:

L-NAME treatment significantly increased both the mean "TPT-R" and "TCR-R" which were significantly shortened by all treatments with insignificant difference between combination treatment of "erythropoietin plus sildenafil" versus sildenafil alone (table 2, figures 3).

Table (2) shows the mean time (seconds \pm SD) to complete relaxation (TCR-S) and to peak tension (TPT-S) in response to single pulse stimulation and the mean time to complete relaxation (TCR-R) and to peak tension (TPT-R) in response to high frequency pulse stimulation of isolated ventricular muscle of treated rats.

\begin{tabular}{|l|l|l|l|l|}
\hline Group & \multicolumn{1}{|c|}{$\begin{array}{c}\text { Mean time to } \\
\text { peak tension of } \\
\text { single pulse } \\
\text { (TPT-S) }\end{array}$} & $\begin{array}{c}\text { Mean time to } \\
\text { complete } \\
\text { relaxation of single } \\
\text { pulse } \\
\text { (TCR-S) }\end{array}$ & $\begin{array}{c}\text { Mean time to } \\
\text { peak tension of } \\
\text { high frequency } \\
\text { pulse (TPT-R) }\end{array}$ & $\begin{array}{c}\text { Mean time to } \\
\text { relaxation of } \\
\text { high frequency } \\
\text { pulse (TCR-R) }\end{array}$ \\
\hline Group “C" & $0.201 \mathrm{sec} \pm 0.09$ & $0.305 \mathrm{sec} \pm 0.12$ & $0.170 \mathrm{sec} \pm 0.02$ & $1.17 \mathrm{sec} \pm 0.04$ \\
\hline Group "L" & $0.249 \mathrm{sec} \pm 0.07$ & $0.409 \mathrm{sec} \pm 0.10$ & $0.379 \mathrm{sec} \pm 0.08^{\mathrm{a}}$ & $1.71 \mathrm{sec} \pm 0.31^{\mathrm{a}}$ \\
\hline Group "L+M" & $0.140 \mathrm{sec} \pm 0.01^{\mathrm{a}, \mathrm{b}}$ & $0.198 \mathrm{sec} \pm 0.04^{\mathrm{a}, \mathrm{b}}$ & $0.164 \mathrm{sec} \pm 0.02^{\mathrm{b}}$ & $1.09 \mathrm{sec} \pm 0.07^{\mathrm{b}}$ \\
\hline Group "L+S" & $0.208 \mathrm{sec} \pm 0.05^{\mathrm{b}}$ & $0.268 \mathrm{sec} \pm 0.03^{\mathrm{a}, \mathrm{b}}$ & $0.187 \mathrm{sec} \pm 0.02^{\mathrm{b}}$ & $1.04 \mathrm{sec} \pm 0.09^{\mathrm{b}}$ \\
\hline Group "L+E" & $0.158 \mathrm{sec} \pm 0.02^{\mathrm{b}}$ & $0.309 \mathrm{sec} \pm 0.09$ & $0.181 \mathrm{sec} \pm 0.03^{\mathrm{b}}$ & $1.01 \mathrm{sec} \pm 0.09^{\mathrm{b}}$ \\
\hline Group "L+S+E" & $0.185 \mathrm{sec} \pm 0.03^{\mathrm{b}}$ & $0.303 \mathrm{sec} \pm 0.03^{\mathrm{b}}$ & $0.160 \mathrm{sec} \pm 0.02^{\mathrm{b}}$ & $1.01 \mathrm{sec} \pm 0.03^{\mathrm{b}}$ \\
\hline
\end{tabular}

Group "C" = Control untreated/normal, Group "L" = L-NAME-treated, Group "L+M" $=\mathrm{L}-\mathrm{NAME}+$ milrinone-treated, Group "L+S" = L-NAME+sildenafil-treated, Group "L+E" = L-NAME+erythropoietin-treated, and Group "L+S+E" = LNAME+sildenafil+erythropoietin-treated.

${ }^{a}$ Significant difference compared to group " $\mathrm{C} \mid$ (normal untreated). ( $\mathrm{p}$ value $\leq 0.05$ )

${ }^{\mathrm{b}}$ Significant difference compared to group "L" (L-NAME-treated). ( $p$ value $\leq 0.05$ ) 


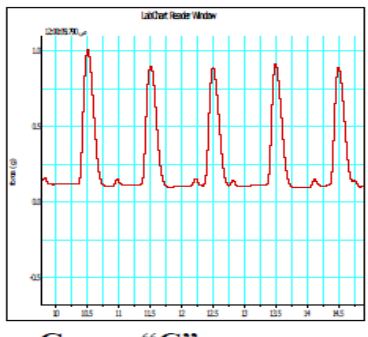

Group "C"

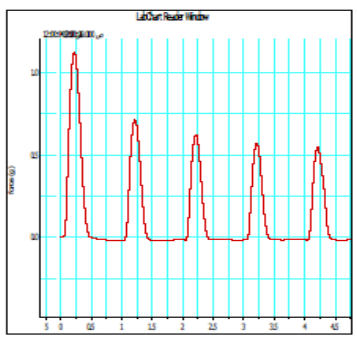

Group "L+S"

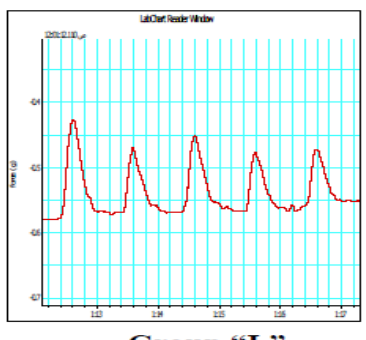

Group " $L "$

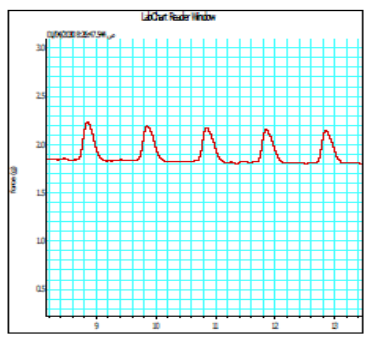

Group "L+E"

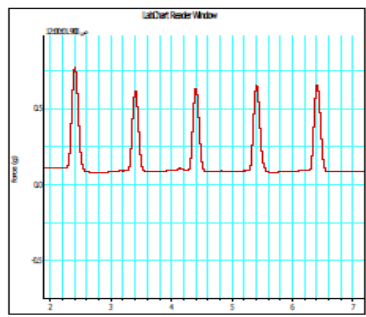

Group "L+M"

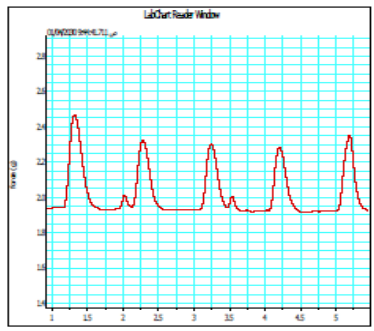

Group "L+S $+\mathbf{E}$ "

Fig. (2): Isometric contractility recording of isolated rat left ventricle in response to single electrical stimulation $(1 \mathrm{~Hz}$, pulse duration $0.1 \mathrm{mS}$, amplitude $20 \mathrm{~mA}$ ) in all animal groups. Group "C" = Control untreated/normal, Group "L" = L-NAME-treated, Group "L+M" = L-NAME+milrinone-treated, Group "L+S" = L-NAME+sildenafiltreated, Group "L+E" = L-NAME+erythropoietin -treated, and Group "L+S+E" = LNAME+sildenafil+erythropoietin-treated.

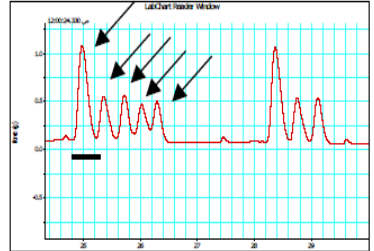

Group "C"

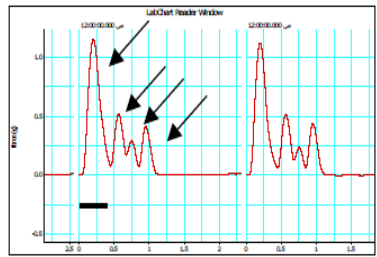

Group "L+S"

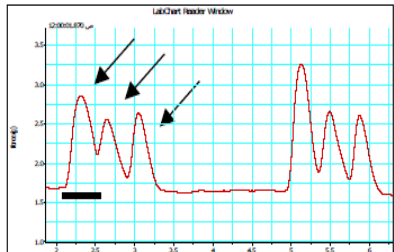

Group "L"

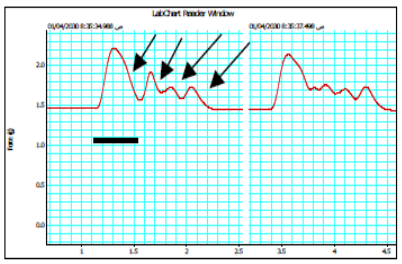

Group "L+E"

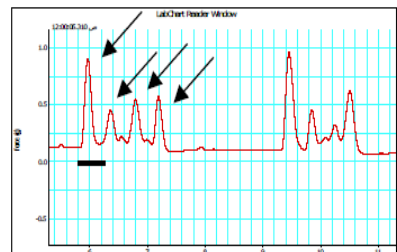

Group "L+M"

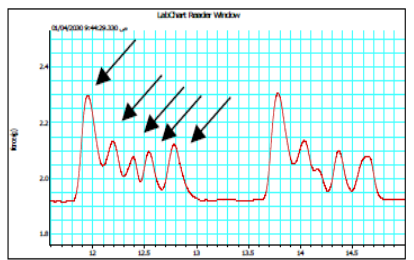

Group "L+S+E"

Fig. (3): Left ventricle cumulative response to 5 consequent electrical impulses $(5 \mathrm{~Hz}$, pulse duration $0.1 \mathrm{mS}$, amplitude $20 \mathrm{~mA}$ ) in different treated groups. Black arrows show number of peaks with five consequent impulses. Group " $C$ " $=$ Control untreated (Normal response), Group "L" = L-NAME-treated, Group "L+M" = LNAME+milrinone-treated, Group " $\mathrm{L}+\mathrm{S}$ " = L-NAME+sildenafil-treated, Group " $\mathrm{L}+\mathrm{E}$ " $=$ L-NAME+erythropoietin-treated, and Group "L+S+E" = LNAME+sildenafil+erythropoietin-treated.

\section{Cardiac morphometeric examination}

Control group "C" showed the regular branching and anastomosis of the cardiac muscle fibers, with central pale nuclei. TS sections revealed uniform cross-sectional 
diameter of the fibers. L-NAME treatment resulted in marked destruction in the form of torn fibers, with loss of cytoplasmic continuity through the whole thickness. Many fibers exhibited ballooning (sign of cell membrane injury), deep acidophilic staining characteristic of cytoplasmic clumping, and pyknotic nuclei indicative of necrosis. Some fibers had lost the nuclei. Changes extended over wide fields in many samples studied. The mean diameters of nuclei and myocytes showed significant increase while nucleus to myocyte ratio didn't change compared to that recorded in group " $\mathrm{C}$ "

Groups " $\mathrm{L}+\mathrm{M}$ " and " $\mathrm{L}+\mathrm{S}$ " showed more regular arrangement of cardiac muscle fibers, many with vesicular nuclei. Areas of necrosis and lysis were more localized. CT areas were increased but without congestion. Other areas showed confluent fibers with minimal CT in between. Overall appearance was markedly improved as compared to Group "L", but not to the control group "C". In addition, the mean diameters of nuclei and myocytes were significantly smaller than that recorded in group "L". To similar extent, group " $\mathrm{L}+\mathrm{E}$ " showed well organized parallel branching fibers with minimal CT in between. Fibers were mostly of smaller diameter (as compared to the control). Most nuclei were vesicular and of good number (populating all of the fibers). Results for this group were thus better improved as compared to the previous group (sildenafil group). Similarly, the mean diameters of nuclei and myocytes were significantly smaller than that in group " $\mathrm{L}$ ".

Addition of erythropoietin to sildenafil treatment showed arrangement of the cardiac muscle fibers most similar to the control group, in the form of regular branching of the parallel fibers. Fibers were of average diameters, and most had vesicular nuclei. $\mathrm{CT}$ areas were not increased. Some injury persisted however, in the form of only partial lysis of areas of fibers, with some congestion. Vacuolations were seen in limited fields. The mean nucleus diameter and the mean myocytes diameter decreased significantly compared to that recorded in group " $L$ ". The nucleus/myocyte ratio didn't change in group "L", while it showed decrease in group " $\mathrm{L}+\mathrm{M}$ ", $\mathrm{L}+\mathrm{S}$ ", " $\mathrm{L}+\mathrm{E}$ " and "L+S+E" compare to control group " $\mathrm{C}$ ". The greatest reduction was detected in sildenafil and the least in combination treatments (Fig. 4 \& Table 3).

Tab. (3): Cardiac morphometric examination of the left ventricle of all rat groups showing the mean nucleus diameter, the mean muscle fiber diameter and nuclei to myocyte diameter ratio.

\begin{tabular}{|l|c|c|c|}
\hline \multicolumn{1}{|c|}{ Group } & $\begin{array}{c}\text { The mean } \\
\text { Nucleus Diameter }\end{array}$ & $\begin{array}{c}\text { The Mean } \\
\text { Muscle Fiber Diameter }\end{array}$ & $\begin{array}{c}\text { Nuclei to Myocyte Diameter } \\
\text { Ratio. }\end{array}$ \\
\hline Group "C" & $4.42 \mu \mathrm{m} \pm 0.33$ & $8.06 \mu \mathrm{m} \pm 0.65$ & $\mathbf{0 . 5 5}$ \\
\hline Group "L" & $5.45 \mu \mathrm{m} \pm 0.59^{\mathrm{a}}$ & $9.85 \mu \mathrm{m} \pm 0.63^{\mathrm{a}}$ & $\mathbf{0 . 5 5}$ \\
\hline Group "L+M" & $3.56 \mu \mathrm{m} \pm 0.35^{\mathrm{b}}$ & $8.49 \mu \mathrm{m} \pm 0.22^{\mathrm{b}}$ & $\mathbf{0 . 3 7}$ \\
\hline Group "L+S" & $2.98 \mu \mathrm{m} \pm 0.30^{\mathrm{b}}$ & $7.82 \mu \mathrm{m} \pm 0.62^{\mathrm{b}}$ & $\mathbf{0 . 4 1}$ \\
\hline Group "L+E" & $3.21 \mu \mathrm{m} \pm 0.31^{\mathrm{b}}$ & $7.81 \mu \mathrm{m} \pm 0.53^{\mathrm{b}}$ & $\mathbf{0 . 4 7}$ \\
\hline Group "L+S+E" & $4.25 \mu \mathrm{m} \pm 0.50^{\mathrm{b}}$ & $8.84 \mu \mathrm{m} \pm 0.75^{\mathrm{b}}$ & \\
\hline
\end{tabular}

Group "C" = Control untreated/normal, Group "L" = L- NAME-treated, Group "L+M" $=\mathrm{L}-\mathrm{NAME}+$ milrinone-treated, Group "L+S" = L- NAME + sildenafil-treated, Group "L+E" = L- NAME + erythropoietin (as darbepoetin-alfa)-treated, and Group " $\mathrm{L}+\mathrm{S}+\mathrm{E}$ " = L- NAME + sildenafil + erythropoietin-treated.

a Significant difference compared to control untreated group "C". ( $p$ value $\leq 0.05)$ 
${ }^{\text {b }}$ Significant difference compared to L-NAME-treated group "L": ( $p$ value $\left.\leq 0.05\right)$.

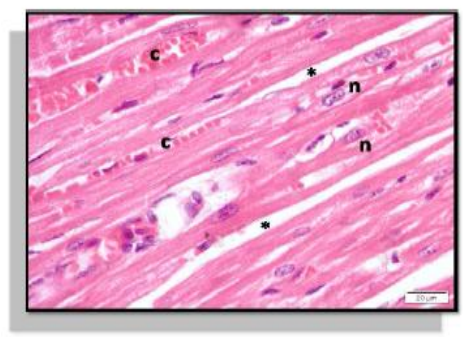

Group "C"

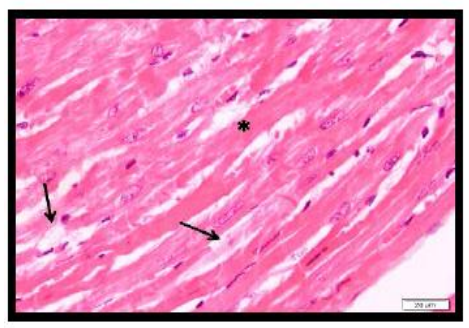

Group "L+S"

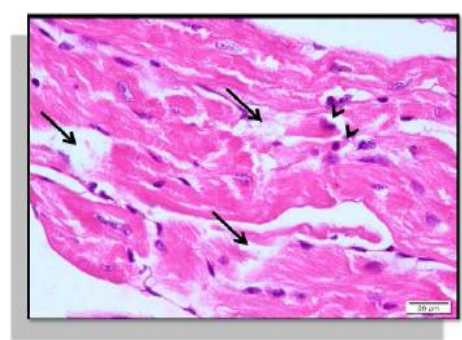

Group "L"

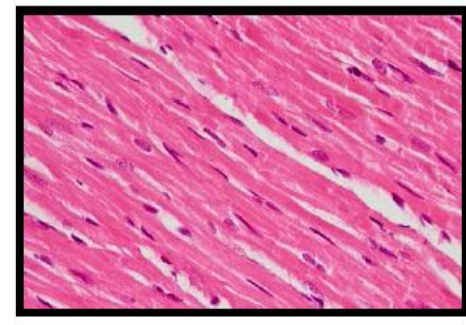

Group "L+E"

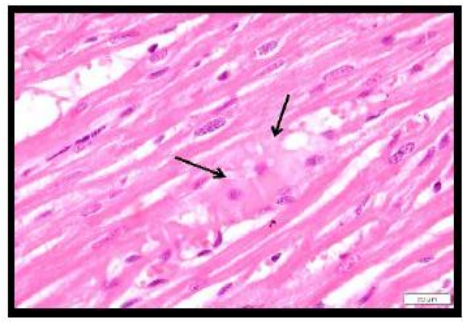

Group "L+M"

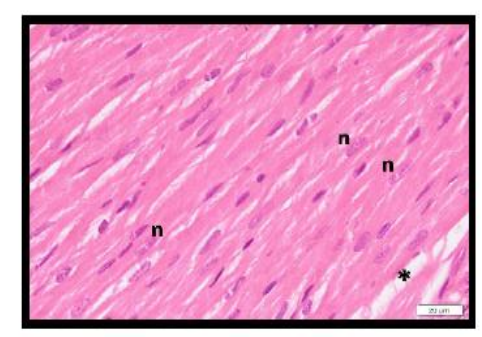

Group "L+S+M"

Fig. (4): LS in ventricular muscle of different treated groups. (H\&E x400). Group "C" (Control) shows parallel branching arrangement of cardiac muscle (n) with parallel capillaries (c) in between. Pale vesicular central nuclei are seen (n), and minimum areas of CT; Group "L" (L-NAME-treated) shows marked disorganization, many pale torn fibers, areas of lysis (arrows) and several dark pyknotic nuclei of myocytes (arrowhead). Group "L+M" (L-NAME +milrinone-treated): shows localized area of lysis and necrosis of myocytes (arrows). Surrounding fibers appear healthy and of normal diameter; Group "L+S" (L-NAME+sildenafil-treated) shows localized area of lysis and necrosis of myocytes (arrows). Surrounding fibers appear healthy and of normal diameter; Group "L+E" (L-NAME+erythropoietin) shows well organized continuous parallel branching fibers, with minimal CT in between. Nuclei in this field are vesicular (active); Group " $\mathbf{L}+\mathbf{S}+\mathbf{E} "$ (L-NAME+sildenafil+erythropoietin-treated) shows arrangement of cardiac muscle cells similar to the control group, with average diameters, vesicular nuclei (n) and regular branching. CT areas are minimal

\section{Discussion}

In the current study, development of diastolic HF in rats induced by 8-week administration of L-NAME was associated with significant reductions in the mean LVEF and LVFS and decreased lusitropy and prolonged contraction time evidenced by increased TCR-R and TPT-R compared to that recorded in the control non-treated animals. On the other hand, milrinone, sildenafil, erythropoietin, and sildenafil+erythropoeitin treatments significantly corrected LVEF and LVFS with nearly similar results. Concerning the effects of the studied drugs on the isometric contraction of isolated left ventricular muscle strip, milrinone and sildenafil significantly accelerated both the prolonged relaxation and contraction (TCR \& TPT) while erythropoietin accelerated only the time to peak contraction i.e. had no effect on lusitropy. Moreover, the addition of erythropoietin to sildenafil had no significant 
corresponding further improvement in these parameters more than that produced by sildenafil alone.

Earlier studies have shown that the effects of the acute, short-term and chronic inhibition of phosphodiesterase-5A (PDE5A) inhibitors on the cardiovascular system in healthy or patients with non-failing hearts were small and not likely to be clinically significant (Jackson et al. 1999; Manfroi et al. 2003 and Ricardi et al. 2010). However, in failing or chronically loaded hearts, the chronic inhibition significantly improved the myocardial dysfunction and LV end diastolic pressure and stiffness with inhibition of myocardial remodeling (Takimoto et al. 2005; Nagayama et al. 2009; Ferreira-Melo et al. 2011 and Westermann et al. 2012). This finding could be explained by increased PDE5A-dependent cGMP-esterase activity in failed hearts, thereby amplifying the cGMP-dependent signaling resulting in much larger changes in PKG-1 activation after PDE5A inhibition. Moreover, cGMP signaling does not depend only on its total myocardial levels as there might be lack of apparent increase in total myocardial cGMP levels (Takimoto et al. 2005). So, the improvement to enhanced PKG-1 activity may be related to cGMP generated by other signaling as nitric oxide synthase (NOS). Consequently, PDE5A inhibition seemed to counter several pathways of kinases and phosphatases activated by the sustained pressure load e.g. calcineurin, $E R K 1 / 2$, and Akt-PI3Ka. Moreover, sildenafil was found to improve sarcoplasmic reticulum handling of calcium with enhanced phospholamban phosphorylation through inhibition of calcineurin and deactivation of PKC $\alpha$ by shifting it away from the outer sarcolemmal membrane (Nagayama et al. 2009). Other effects attributed to chronic PDE5 inhibition include increased vascular endothelial growth factor (VEGF), phosphorylation of Akt, IL-8/Gro mRNA expression, and expression of anti-apoptotic protein Bcl-2 and Bax in addition to lowering of gene and protein expressions of MMP9 and the number of CD40-positively stained cells (Lin et al. 2010). Furthermore, chronic PDE5 inhibition reduces endoplasmic reticulum (ER) stress markers and apoptosis that elevated with increased myocardial PDE5 expression in HF and restores intracellular $\mathrm{Ca}^{2+}$ balance (Gong et al. 2013).

On the contrary, Degen et al. (2015), denied any role for PDE5 in treatment of $\mathrm{HF}$ as they were unable to detect PDE5 in any of the cardiac tissue lysates examined from humans or experimental models of HF. Furthermore, the randomized clinical trial "RELAX" on the effect of 24-week sildenafil treatment in HFpEF not only failed to show significant benefit but it also found more deterioration with tendency for adverse effects. They reached a conclusion that sildenafil has no clinical benefit in the general HF $p$ EF population. However, they vindicated this failure by the possibility that the study population, specifics of the therapeutic intervention and endpoints might need consideration (Redfield et al. 2013). On the other hand, Nagendran et al. (2007), reported increased expression of PDE5 in the hypertrophied human right ventricle and acute inhibition of PDE5 improves contractility due to an elevation in cAMP (not cGMP) and enhancement of protein kinase A (i.e. not PKG).

Several studies have established that erythropoietin (EPO) has effects beyond hematopoiesis. They reported that EPO at a dose that does not increase hematocrit, can induce neovascularization and improves both myocardial contractility and relaxation following myocardial infarction with an increased expression of the VEGF (Westenbrink et al, 2007 and Hefer et al. 2012) and Akt-eNOS activation (Urao et al. 2006). However, our results did not show significant improvement in myocardial 
relaxation. The cardiac effects of EPO were attributed to phosphatidylinositol-3-kinase (PI3-K) and that protein kinase $\mathrm{C}(\mathrm{PKC})$ is the likely down-stream effector of this pathway. Furthermore, a novel $\left(\mathrm{Ca}^{2+}\right.$ independent) $\mathrm{PKC}$ isozymes (primarily PKC $\varepsilon$ ) are probably the primary mediators involved in the EPO contractile effect rather than the classical PKC $\left(\mathrm{Ca}^{2+}\right.$ dependent) isozymes whereas the lusitropic effects of EPO were suggested to be due to an increase in the recoil force of the muscles' elastic elements, e.g. titin, that result from the increased extent of sarcomere shortening (Hefer et al. 2012). However, clinical studies showed no significant effects on contractile state, left ventricular mass or estimated LVEDP even with correction of anemia in elderly patients with HFpEF (Green et al. 2013).

In the present study, the histologic examination of the left ventricles from group "L" showed marked injury of the cardiac myocytes with necrosis over wide fields compared to that measured in control " $\mathrm{C}$ " group. Meanwhile, sildenafil and milrinone treatment resulted in comparable partial but significant improvement in the histologic derangement. Erythropoietin treatment showed more better histologic appearance whereas the "erythropoietin plus sildenafil" combination treatment showed the best histologic picture in all of the treated groups with nearly normal appearance and minimal injury.

Concerning the cardiac morphometric effects, most of the previously mentioned studies on sildenafil showed associated improvement in the pathologic morphometry of the cardiac muscles in HF. However, this improvement was not complete. On the other hand, beside the improvement in cardiac function associated with its hematopoietic activity, EPO has showed significant direct cellular protective effects with reduction of the infarct size, apoptosis (Parsa et al. 2004), myocyte atrophy and degeneration, myocardial fibrosis, and inflammatory cell infiltration (Li et al. 2006) in cardiac tissue. Many mechanisms were found to be related to its tissue protective effects. One of these findings was its ability to activate Jak/STAT (receptor-associated Janus family tyrosine kinase/Signal Transducer and Activator of Transcription proteins) and PI3K/Akt (phosphatidylinositol 3 phosphate kinase/protein kinase B) signaling pathways detected both in vivo and in vitro that can account for its anti-apoptotic activity. In addition, Li et al. (2006), reported that EPO increased the transcriptional factor GATA-4 that enhances the sarcomeric proteins (MHC, troponin I, and desmin) and inhibited increased cyclooxygenase-2 expression and restored activation of ERKs (extracellular signalregulated kinases). Moreover, EPO was found to increase EPO receptors (EPOR) and VEGF expression with inhibition of cardiac fibrosis by reducing TGF- $\beta$ expression (Lu et al. 2012) that can explain its beneficial effect against myocardial hypertrophy and fibrosis (Wang et al. 2016). However, Parsa et al. (2004) found no anti-apoptotic activity or beneficial effect related to activation of PI3K/Akt or Jak/STAT and Pessoa et al. (2012), demonstrated that EPO failed to improve cardiac fibrosis in the right ventricle.

With regard to QT interval, the current study showed significant prolongation by L-NAME treatment which was shortened by sildenafil and milrinone only while EPO failed. An early study showed that sildenafil exerted direct cardiac electrophysiological effects similar to class III antiarrhythmic agents at high concentrations (Geelen et al. 2000) that may explain some cases of sudden death during sildenafil treatment. In addition, sildenafil in patients with HF, through its reflex vasodilatory action, can affect the autonomic system with preponderance to sympathetic over parasympathetic activity. 
These changes could alter QT dynamics. Both changes could favor the onset of lethal ventricular arrhythmias but sildenafil has no direct effect on cardiac repolarization at the dose usually taken for erectile dysfunction (Piccirillo et al. 2002). Moreover, therapeutic and supratherapeutic doses produced only small clinically insignificant increases in the QTcF interval (Morganroth et al. 2004). On the contrary, Chiang et al. (2002) found no prolongation of the action potential duration by sildenafil in therapeutic ranges and they even reported shortening by higher concentration through blocking of L-type $\mathrm{Ca}^{+2}$ channels. Furthermore, prolongation of the QT interval was reported in dogs treated with sildenafil prior to coronary artery ligation. However, ischemia-induced ventricular arrhythmias were reduced by sildenafil (Nagy et al. 2004)

Conclusion: Chronic sildenafil treatment was able to improve cardiac functions mainly by accelerating diastolic relaxation. Sildenafil partially improved the histologic derangement in L-NAME-induced HFpEF; whereas EPO, despite its weak direct benefit on cardiac function, had better tissue protective activity. Finally, combination of EPO plus sildenafil produced the best results of the tested treatment regimens and could be superior to each drug alone on long term, possibly by reducing muscle atrophy associated with sildenafil. Finally, it is noteworthy to test this combination clinically in patients with diastolic HF.

\section{Acknowledgements}

We thank Prof. Dr. Moustafa S Fadel, Professor and Head of Diagnostic Imaging and Endoscopy Unit, Animal Reproduction Research Institute, Egypt, for his meticulous work in doing and analysis of the echocardiography.

\section{REFERENCES}

Abbott D, Comby P, Charuel C, Graepel P, Hanton G, Leblanc B, Lodola A, Longeart L, Paulus G, Peters C and Stadler J.(2004) Preclinical safety profile of sildenafil. Int J Impot Res 2004;16(6):498-504.

Afzal F, Aronsen JM, Moltzau LR, Sjaastad I, Levy FO, Skomedal T, Osnes JB and Qvigstad E. (2011) Differential regulation of b2-adrenoceptor-mediated inotropic and lusitropic response by PDE3 and PDE4 in failing and non-failing rat cardiac ventricle. British Journal of Pharmacology 2011;162:54-71.

Chiang CE, Luk HN, Wang TM and Ding PYA. (2002) Effects of sildenafil on cardiac repolarization. Cardiovascular Research 2002;55(2):290-299.

Curl, C. L., Delbridge, L. M., \& Wendt, I. R. (2008) Sex differences in cardiac muscle responsiveness to $\mathrm{Ca}^{2+}$ and L-type $\mathrm{Ca}^{2+}$ channel modulation. European journal of pharmacology 2008;586(1):288-292.

Degen CV, Bishu K, Zakeri R, Ogut O, Redfield MM and Brozovich VF.(2015) The Emperor's New Clothes: PDE5 and the Heart. PLOS ONE 2015;March 6,

Ferreira-Melo SE, Demacq C, Lacchini S, Krieger JE, Irigoyen MC and Moreno H.(2011) Sildenafil preserves diastolic relaxation after reduction by L-NAME and increases phosphodiesterase-5 in the intercalated discs of cardiac myocytes and arterioles. CLINICS, 2011;66(7):1253-1258 
Fukuda N, Granzier HL, Ishiwata SI and Kurihara, S.(2008) Physiological functions of the giant elastic protein titin in mammalian striated muscle. The Journal of Physiological Sciences 2008;58(3):151-159.

Fukuta H, Goto T, Wakami $K$ and Ohte N.(2016) Effects of drug and exercise intervention on functional capacity and quality of life in heart failure with preserved ejection fraction: a meta-analysis of randomized controlled trials. Eur $\mathrm{J}$ Prev Cardiol 2016;23:78-85.

Geelen P, Drolet B, Rail J, Berube J, Daleau P, Rousseau G, Cardinal R, O'Hara GE and Turgeon J.(2000) Sildenafil (Viagra) prolongs cardiac repolarization by blocking the rapid component of the delayed rectifier potassium current. Circulation 2000;102:275-277.

Gong W, Duan Q, Cai Z, Chen C, Ni L, Yan M, Wang X, Cianflone K, and Wang DW.(2013) Chronic inhibition of cGMP-specific phosphodiesterase 5 suppresses endoplasmic reticulum stress in heart failure. British journal of pharmacology 2013;170(7):1396-1409.

Green P, Babu BA, Teruya S, Helmke S, Prince M, and Maurer MS.(2013) Impact of Epoetin Alfa on LV Structure, Function, and Pressure-Volume Relations as Assessed by Cardiac Magnetic Resonance - The Heart Failure Preserved Ejection Fraction (HFpEF) Anemia Trial. Congest Heart Fail 2013;19(4):172-179.

Guazzi, M, Vicenzi, M, Arena, R and Guazzi, M. D.(2011) PDE5 inhibition with sildenafil improves left ventricular diastolic function, cardiac geometry, and clinical status in patients with stable systolic heart failure results of a 1-year, prospective, randomized, placebo-controlled study. Circulation: Heart Failure, 2011;4(1): 8-17.

Hefer D, Yi T, Selby DE, Fishbaugher DE, Fishbaugher DE, Tremble SM, Gogo P, LeWinter MM, Meyer M, Palmer BM and VanBuren P.(2012) Erythropoietin induces positive inotropic and lusitropic effects in murine and human myocardium. J Mol Cell Cardiol 2012;52(1):256-263.

Jackson G, Benjamin N, Jackson N, and Allen MJ (1999): Effects of sildenafil citrate on human hemodynamics. Am J Cardiol 1999;83:13C-20C.

Jain P, Brown EJ, Langenback EG, Raeder E, Lillis O, Halpern J and Mannisi JA.(1991) Effects of milrinone on left ventricular remodeling after acute myocardial infarction. Circulation. 1991;84:796-804

Kass, DA, Takimoto E, Nagayama T and Champion HC.(2007) Phosphodiesterase regulation of nitric oxide signaling. Cardiovascular research 2007;75(2):303-314.

Li L, Takemura G, Li Y, Miyata S, Esaki M, Okada H, Kanamori H, Khai NC, Maruyama R, Ogino A, Minatoguchi S, Fujiwara T and Fujiwara H.(2006) Preventive Effect of Erythropoietin on Cardiac Dysfunction in DoxorubicinInduced Cardiomyopathy. Circulation 2006;113:535-543.

Lin Y-C, Leu S, Sun C-K, Yen C-H, Kao Y-H, Chang L-T, Tsai T-H, Chua S, Fu M, Ko S-F, Wu C-J, Lee F-Y and Yip H-K.(2010) Early combined treatment with sildenafil and adipose-derived mesenchymal stem cells preserves heart 
function in rat dilated cardiomyopathy. Journal of Translational Medicine 2010;8:88-103.

Lu J, Yao Y-y, Dai Q-m, Ma G-s, Zhang S-f, Cao L, Ren L-q and Liu N-f.(2012) Erythropoietin attenuates cardiac dysfunction by increasing myocardial angiogenesis and inhibiting interstitial fibrosis in diabetic rats. Cardiovascular Diabetology 2012;11:105-115.

Maeda CY, Fernandes TG, Timm HB and Irigoyen MC.(1995) Autonomic dysfunction in short-term experimental diabetes. Hypertension 1995;26(6):11001104.

Manfroi WC, Caramori PR, Zago AJ, Melchior R, Zen V, Accordi M, Gutierres D and Noer C.(2003) Hemodynamic effects of sildenafil in patients with stable ischemic heart disease. Int J Cardiol 2003;90:153-157.

Morganroth J, Ilson BE, Shaddinger BC, Dabiri GA, Patel BR, Boyle DA, Sethuraman VS and Montague TH.(2004) Evaluation of Vardenafil and Sildenafil on Cardiac Repolarization. Am J Cardiol 2004;93:1378-1383.

Nagayama T, Hsu S, Zhang M, Koitabashi N, Bedja, D, Gabrielson KL, Takimoto E and Kass DA.(2009) Sildenafil stops progressive chamber, cellular, and molecular remodeling and improves calcium handling and function in hearts with pre-existing advanced hypertrophy caused by pressure overload. Journal of the American College of Cardiology 2009;53(2):207-215.

Nagendran J, Archer SL, Soliman D, Gurtu V, Moudgil R, Haromy A, St. Aubin C, Webster L, Rebeyka IM, Ross DB, Light PE, Dyck JRB and Michelakis ED.(2007) Phosphodiesterase Type 5 is Highly Expressed in the Hypertrophied Human Right Ventricle, and Acute Inhibition of Phosphodiesterase Type 5 Improves Contractility. Circulation 2007;116:238-248

Nagy O, Hajnal A, Parratt JR and Vegh A.(2004) Sildenafil (Viagra) reduces arrhythmia severity during ischaemia $24 \mathrm{~h}$ after oral administration in dogs. British Journal of Pharmacology 2004;141:549-551.

Parsa CJ, Kim J, Riel RU, Pascal LS, Thompson RB, Petrofski JA, Matsumoto K, Stamler JS and Koch WJ.(2004) Cardioprotective Effects of Erythropoietin in the Reperfused Ischemic Heart, A Potential Role For Cardiac Fibroblasts. Journal of Biological Chemistry 2004;279(20):20655-20662.

Paulus WJ and Tschöpe C.(2013) A novel paradigm for heart failure with preserved ejection fraction: comorbidities drive myocardial dysfunction and remodeling through coronary microvascular endothelial inflammation. Journal of the American College of Cardiology 2013;62(4):263-271.

Pessoa FG, Ramires FJA, Fonoff AMO, Fonseca KCB, Salemi VMC, Fernandes F, Mady C.(2012) The Role of Erythropoietin Upon Myocardial Fibrosis ABSTRACT Abstracts From the 16th Annual Scientific Meeting, HFSA, Journal of Cardiac Failure 2012;18(8):S23(Supplement)

Piccirillo G, Nocco M, Lionetti M, Moisè A, Naso C, Marigliano V, and Cacciafesta M.(2002) Effects of sildenafil citrate (Viagra) on cardiac repolarization and on 
autonomic control in subjects with chronic heart failure. Am Heart $\mathbf{J}$ 2002;143:703-10.

Pokreisz P, Vandenwijngaert S, Bito V, Van den Bergh A, Lenaerts I, Busch C, Marsboom G, Gheysens O, Vermeersch P, Biesmans L, Liu X, Gillijns H, Pellens M, Van Lommel A, Buys E, Schoonjans L, Vanhaecke J, Verbeken E, Sipido K, Herijgers P, Bloch KD and Janssens SP.(2009) Ventricular phosphodiesterase 5 expression is increased in patients with advanced heart failure and contributes to adverse ventricular remodeling after myocardial infarction in mice. Circulation 2009;119(3):408-416.

Redfield MM, Chen HH, Borlaug BA, Semigran MJ, Lee KL, Lewis G, LeWinter MM, Rouleau JL, Bull DA, Mann DL, Deswal A, Stevenson LW, Givertz MM, Ofili EO, O'Connor CM, Felker GM, Goldsmith SR, Bart BA, McNulty SE, Ibarra JC, Lin G, Oh JK, Patel MR, Kim RJ, Tracy RP, Velazquez EJ, Anstrom KJ, Hernandez AF, Mascette AM and Braunwald E.(2013) Effect of phosphodiesterase-5 inhibition on exercise capacity and clinical status in heart failure with preserved ejection fraction: a randomized clinical trial. JAMA 2013;309(12):1268-77.

Ricardi U, Gontero P, Ciammella P, Badellino S, Valentino F, Munoz F, Guarneri A, Rondi N, Moretto F, Filippi AR, Ragona R and Tizzani A.(2010) Efficacy and safety of tadalafil $20 \mathrm{mg}$ on demand vs. tadalafil $5 \mathrm{mg}$ once-a-day in the treatment of post-radiotherapy erectile dysfunction in prostate cancer men: a randomized phase II trial. J Sex Med 2010;7(8):2851-9.

Rocha R, Stier CT, Kifor JrI, Ochoa-Maya MR, Rennke HG, Williams GH, and Adler GK.(2000) Aldosterone: A Mediator of Myocardial Necrosis and Renal Arteriopathy Endocrinology 2000;141(10):3871-3878

Satoh, N., Sato, T., Shimada, M., Yamada, K., \& Kitada, Y.(2001) Lusitropic effect of MCC-135 is associated with improvement of sarcoplasmic reticulum function in ventricular muscles of rats with diabetic cardiomyopathy. Journal of Pharmacology and Experimental Therapeutics 2001;298(3):1161-1166.

Takimoto E, Champion HC, Li M, Belardi D, Ren S, Rodriguez ER, Bedja D, Gabrielson KL, Wang Y and Kass DA.(2005) Chronic inhibition of cyclic GMP phosphodiesterase 5A prevents and reverses cardiac hypertrophy. Nature Medicine 2005;11(2):214-222

Tanida M, Niijima A, Fukuda Y, Sawai H, Tsuruoka N, Shen J, Yamada S, Kiso Y, and Nagai K.(2005) Dose-dependent effects of L-carnosine on the renal sympathetic nerve and blood pressure in urethane-anesthetized rats. Am J Physiol Regul Integr Comp Physiol 2005;288:R447-R455.

Urao N, Okigaki M, Yamada H, Aadachi Y, Matsuno K, Matsui A, Matsunaga S, Tateishi K, Nomura T, Takahashi T, Tatsumi T and Matsubara H.(2006) Erythropoietin-Mobilized Endothelial Progenitors Enhance Reendothelialization via Akt-Endothelial Nitric Oxide Synthase Activation and Prevent Neointimal Hyperplasia. Circ Res 2006;98:1405-1413.

Vasan RS, Xanthakis V, Lyass A, Andersson C, Tsao C, Cheng S, Aragam J, Benjamin EJ and Larson MG.(2018) Epidemiology of Left Ventricular 
Systolic Dysfunction and Heart Failure in the Framingham Study: An Echocardiographic Study Over 3 Decades. JACC Cardiovasc Imaging 2018,11(1):1-11

Wang L-P, Yang X-H, Wang X-J, Li S-M, Sun N and Zhang T.(2016) Erythropoietin Decreases the Occurrence of Myocardial Fibrosis by Inhibiting the NADPH-ERK-NF-кB Pathway. Cardiology, 2016;133:97-108.

Westenbrink BD, Lipsic E, van der Meer P, van der Harst P, Oeseburg H, Du Marchie Sarvaas GJ, Koster J, Voors AA, van Veldhuisen DJ, van Gilst WH and Schoemaker RG.(2007) Erythropoietin improves cardiac function through endothelial progenitor cell and vascular endothelial growth factor mediated neovascularization. European heart journal 2007;28(16):2018-2027.

Westermann D, Becher PM, Lindner D, Savvatis K, Xia Y, Fröhlich M, Hoffmann S, Schultheiss HP and Tschöpe C.(2012) Selective PDE5A inhibition with sildenafil rescues left ventricular dysfunction, inflammatory immune response and cardiac remodeling in angiotensin II-induced heart failure in vivo. Basic Res Cardiol 2012;107(6):308-319. 
الإريثروبيوتين له حماية خلوية و علاجية إضافية للسيلاينافيل في هبوط القلب الإنبساطي في

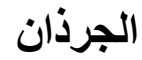

اللسادة الاكاترة

عصام فؤاد العلقامي ، 'هشام عطية عوض ، 'سهير عادل عبد الو احد ، 'مير ا فاروق يوسف ، 'ايناس أنس حرب

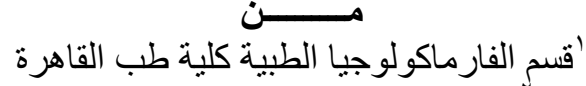

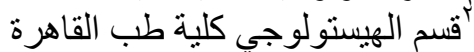

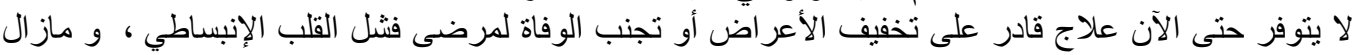

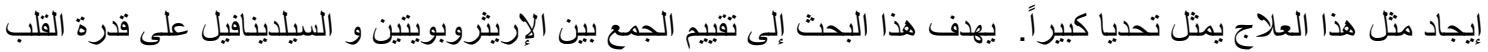

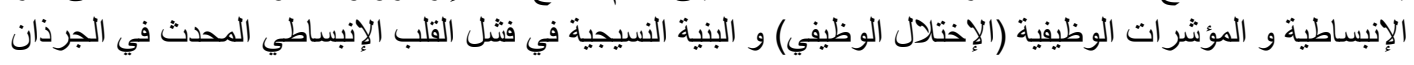

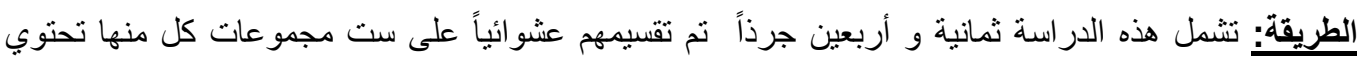

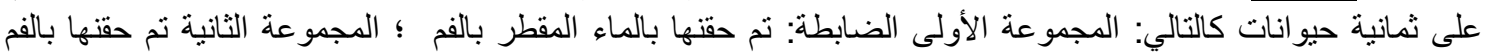

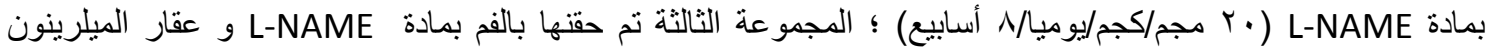

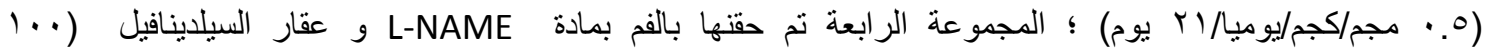

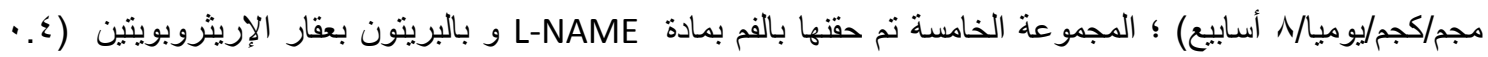

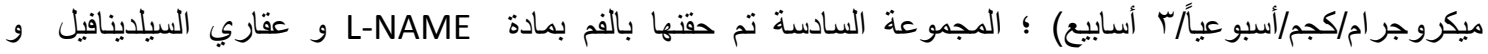
الإريثروبويتين.

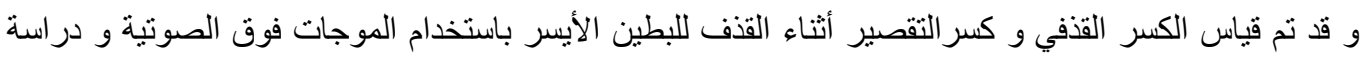

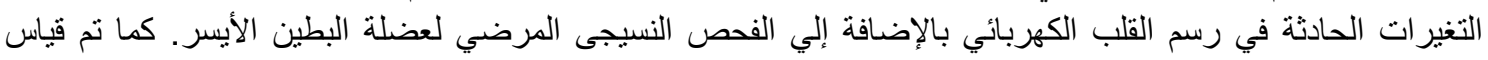

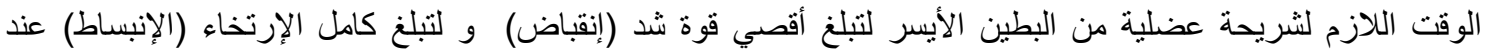
تنبيهها بنبضة واحدة أو نبضات كهربائية متعددة مع ثبات طولها.

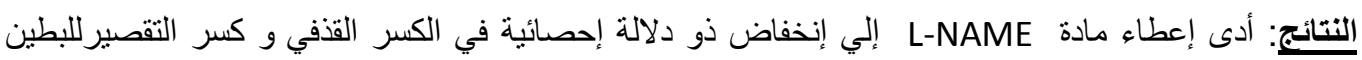

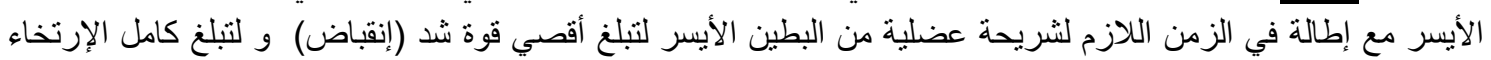

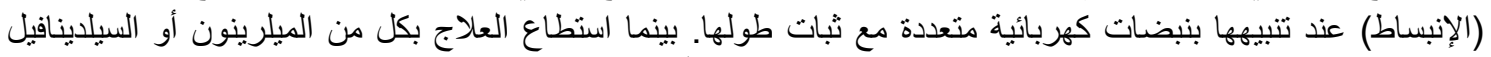

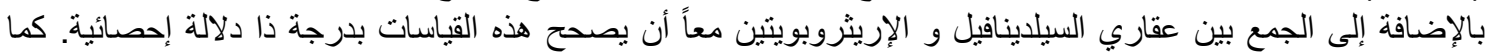

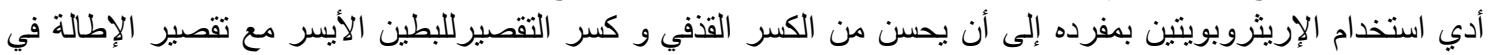

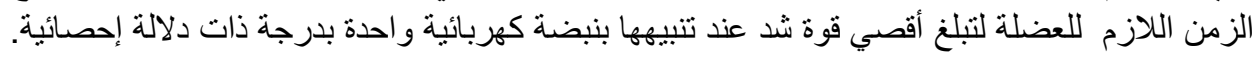

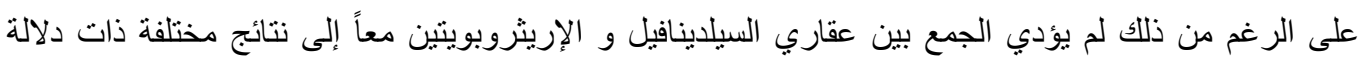

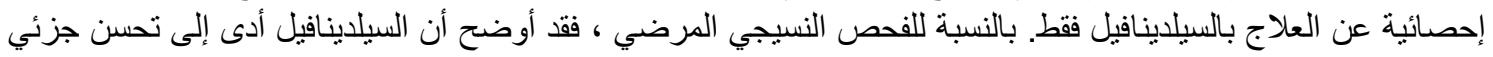

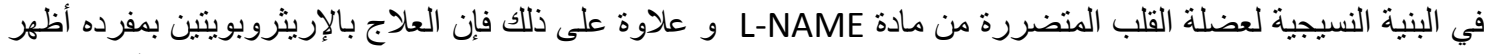

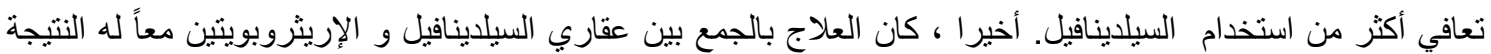

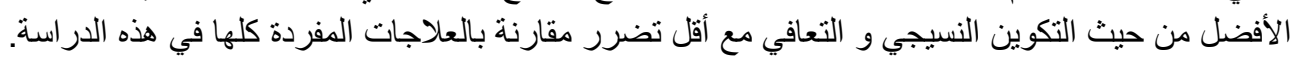

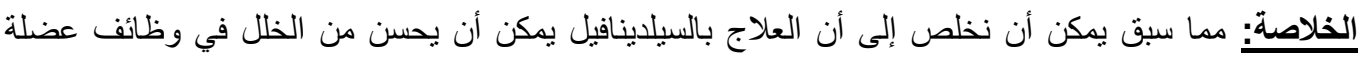

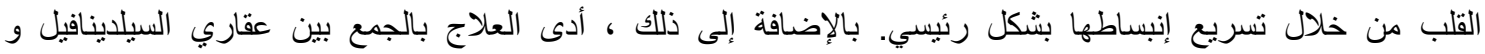

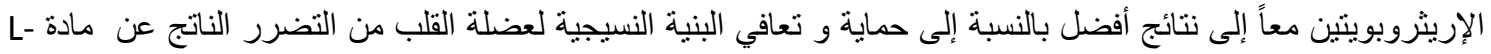
NAME

الكلمات المفتاحية: فثنل القلب الإنبساطي ، موجات صوتية على القلب (إيكوكارديوجر افي) ، الإني ، الفحص النسيجى المرضي

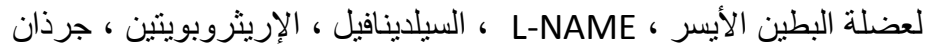

